\title{
Prospective Placebo-controlled Randomized Trial to compare the Efficacy of Ketamine as an Adjuvant to Epidural Steroids in preventing Repeat Blocks in Chronic Low Back Pain
}

\author{
${ }^{1}$ Ruchi Gupta, ${ }^{2}$ Chashamjot Bawa, ${ }^{3}$ Saru Singh, ${ }^{4}$ Lakshmi Mahajan, ${ }^{5}$ Bhanupreet Kaur, ${ }^{6}$ Tavleen Kaur
}

\begin{abstract}
Introduction: Low back pain behaves as a "silent epidemic," ranking first among complications related to work. Often there is a large gap between a patient's desired pain reduction and the minimum percentage of improvement that would make a treatment worthwhile. Consequently, debate continues as to the value of epidural steroid injections, supremacy of one adjuvant over others, various doses, and concentrations in optimizing pain management.
\end{abstract}

Objective: To compare the efficacy of ketamine vs normal saline as an adjuvant to epidural steroids in chronic low back pain.

Study design: Randomized prospective placebo-controlled study.

Materials and methods: The study was conducted on 60 patients of age group 18 to 70 years having chronic lower backache with or without radiculitis of minimum 3 months duration and having no relief with conventional treatment. The patients selected were randomly allocated into two groups of 30 patients each: Group I ( $n=30$ ) given triamcinolone $40 \mathrm{mg}$, preservative-free ketamine $30 \mathrm{mg}(0.6 \mathrm{~mL})$ made up to $6 \mathrm{~mL}$ solution with $0.25 \%$ bupivacaine and group II $(n=30)$ given $0.6 \mathrm{~mL}$ normal saline instead of ketamine.

Outcome measures: The primary outcome measured was number of patients requiring repeat blocks and number of repeat blocks administered in 3 months. Other outcome measures were functional improvement quantified by visual analog scale (VAS) and Oswestry disability index (ODI) as well as improvement in psychological status by depression scoring, all taken at 2 weeks interval for 3 months. The periprocedural complications were also noted at the end of the study.

Results: In managing lumbar radicular pain with lumbar epidural steroid injection (LESI), ketamine's role as an adjuvant

\footnotetext{
${ }^{1}$ Professor and Head, ${ }^{2}$ Senior Resident, ${ }^{3,4}$ Associate Professor ${ }^{5,6}$ Postgraduate

${ }^{1-6}$ Department of Anesthesia, Sri Guru Ram Das Institute of Medical Sciences and Research, Amritsar, Punjab; BPS Government Medical College for Women, Sonepat, Haryana India
}

Corresponding Author: Ruchi Gupta, 243, Maqbool Road Amritsar-143001, Punjab, India, e-mail: drruchiogrd@gmail.com proved to be advantageous for long-term relief by its inhibition of dorsal horn "wind up" phenomenon through N-methylD-aspartate (NMDA) receptor antagonism, thus reducing frequency of repeat blocks in group II (ketamine).

Conclusion: Thus to conclude, ketamine's advantage as a drug that prolongs pain relief from LESI is an avenue for further research and promises a bright future in the field of interventional pain medicine.

Keywords: Central neuropathic pain, Epidural steroids, Interlaminar, Ketamine, Low back pain, Nociceptive pain, Radiculopathy, Spinal pain.

How to cite this article: Gupta R, Bawa C, Singh S, Mahajan L, Kaur B, Kaur T. Prospective Placebo-controlled Randomized Trial to compare the Efficacy of Ketamine as an Adjuvant to Epidural Steroids in preventing Repeat Blocks in Chronic Low Back Pain. Curr Trends Diagn Treat 2017;1(1):15-21.

\section{Source of support: Nil}

\section{Conflict of interest: None}

\section{INTRODUCTION}

Low backache (LBA) is the commonest problem seen in pain clinics today with diverse pathophysiologies like lumbar disk herniation, degenerative disk disease, spondylolisthesis, and spinal canal stenosis. Among various treatment modalities, epidural steroid injections are the safest, most effective, and economical treatment that reduces the period of hospitalization and analgesic intake. It also facilitates early rehabilitative programs. ${ }^{1}$

Numerous studies approve epidural steroids for short-term relief in chronic low back pain. They are known to stay in the epidural space for about 2 to 3 weeks exerting antiinflammatory action to decrease the perineural edema, and thus provide analgesia. ${ }^{2}$ Also, they may require repeated administration according to the patient's satisfaction and need maximum of 3 to 4 injections in a year. ${ }^{3}$

Despite the fact that epidural steroids work at the site of nociception to alleviate chronic pains, they are associated with side effects more so on repeated injections or high doses like weight gain, fluid retention, flushing, sleep disturbances, hypothalamic-pituitaryadrenal and hypothalamic-pituitary-ovarian depression, 
dysphonia, increased blood sugar, visual disturbances, osteoporosis, etc.

Low back pain triggering from multiple pathophysiological components or centrally sensitized neuropathic changes (mixed pain disorders) set up intricate neuronal circuits where epidural steroids alone may fail. Based on recent concepts of pain, inflammation causes increase in glutamate and aspartate, magnifying dorsal horn responses to 20 times by "wind up" phenomenon. ${ }^{4,5}$ $\mathrm{N}$-methyl-D-aspartate (NMDA) receptor antagonists, like ketamine, prevent induction and maintenance of this central sensitization, thus acting as an analgesic adjunct. Hence, a study was proposed to elicit ketamine's efficacy to epidural steroids in LBA patients. We hypothesized that addition of ketamine may provide better clinical outcome and reduce the frequency of repeat blocks.

\section{AIMS AND OBJECTIVES}

It evaluates the efficacy of ketamine as an adjuvant to epidural steroid injections in terms of:

- Number of patients requiring repeat block and total number of repeat blocks using epidural steroids with or without ketamine (primary outcome)

- Improvement in visual analog scale (VAS) and quality of life scores (secondary outcome)

- Complications associated with the procedure especially with epidural ketamine use (tertiary outcome).

\section{MATERIALS AND METHODS}

A prospective randomized blinded study was proposed to be conducted on 60 patients of chronic lower backache attending pain clinic in a tertiary care center after obtaining approval from hospital Ethics Committee, and a prior written informed consent from the patients.

Patients in the age group 18 to 70 years, history of LBA with or without radiculitis of minimum 3 months duration, and no relief with conservative treatment were included in the study. The exclusion criteria taken for the study were any contraindications to administer epidural anesthesia, history of allergy to anesthetic drugs, psychiatric history, spinal cord deformities, previous lumbar epidural steroid injection (LESI), fibromyalgia, history of spinal surgery, cauda equina syndrome, opioid habituation, and pregnancy.

During the study, 97 patients with LBA were screened for the study. Out of these, 11 patients responded to physiotherapy and/or medication alone, 3 patients diagnosed fibromyalgia, 10 patients refused to participate, 2 patients failed to lie in prone position due to comorbidities, 10 patients could not come for follow-up, and 1 patient reported drug allergy from local anesthetics. Thus, 60 patients were randomized and included into two groups of 30 each and given $40 \mathrm{mg}$ triamcinolone with $0.6 \mathrm{~mL}(30 \mathrm{mg})$ ketamine made up to $6 \mathrm{~mL}$ with $0.25 \%$ bupivacaine in group I, while the same drug solution with $0.6 \mathrm{~mL}$ normal saline given as placebo in group II (Flow Chart 1).

The blind study was conducted using envelopes assigning patients into two groups and was opened by the anesthesiologist performing the procedure who did not participate in the observation part of the study. Similarly, the preoperative and postoperative assessors were blinded to the participant's assignment groups.

All patients were evaluated for pain using VAS and quality of life by Oswestry disability index (ODI)

Flow Chart 1: Sampling process

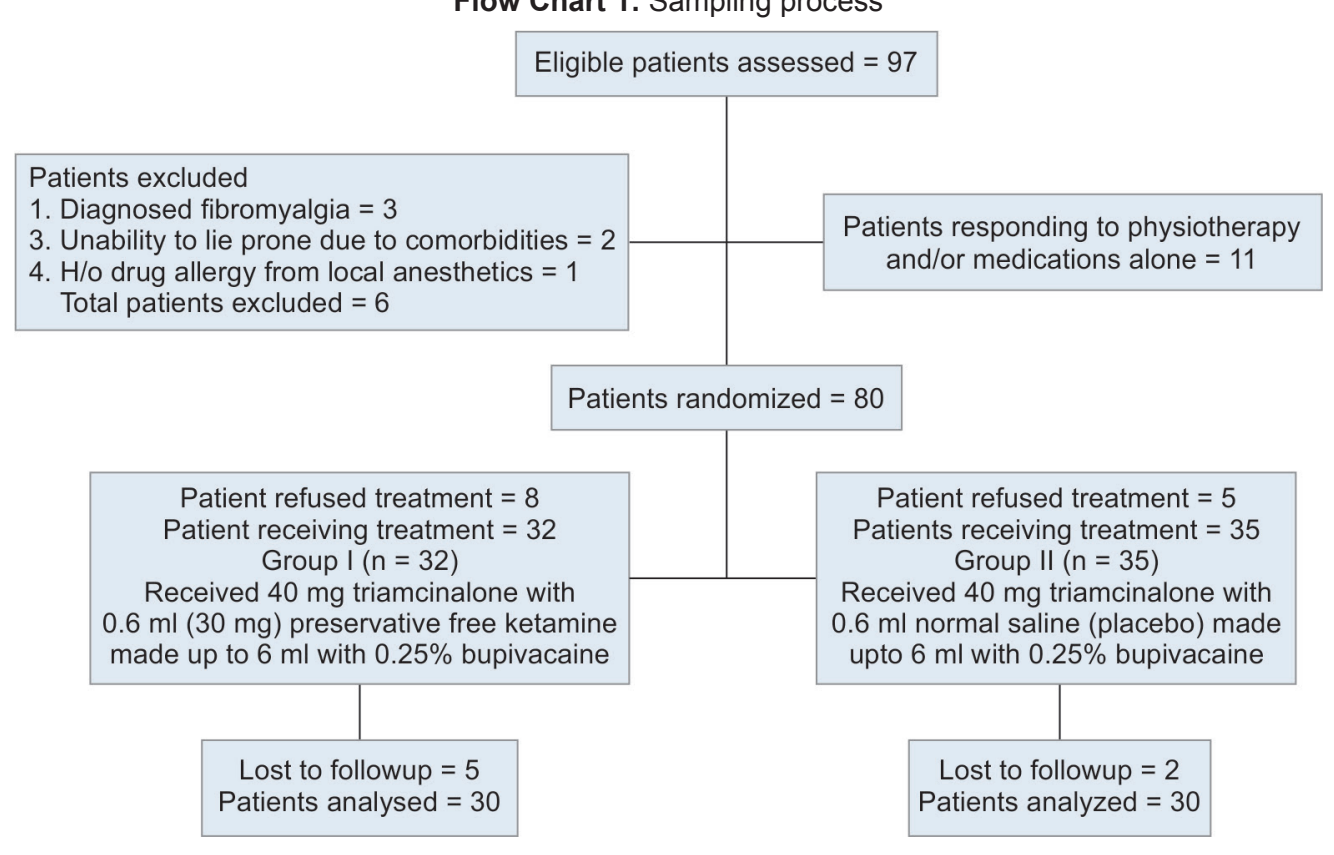


score and depression score. Neurological examination was done and magnetic resonance imaging (MRI) findings noted. In addition, a detailed medical history was taken and the patients informed regarding side effects that he/she might suffer postprocedure like those with ketamine.

Oral midazolam $7.5 \mathrm{mg}$ was given 2 hours before shifting patient to operation theatre (OT) and standard monitoring applied after making prone position. Lumbar epidural block was given with 18G Touhy's needle according to the site of lesion by median interlaminar approach using fluoroscopic guidance. Fluoroscopic findings were observed using a contrast injection, and only after confirmation of needle placement by epidurographical dorsal spread, drugs were given according to group allocation.

Patient's vitals were checked and pain relief was assessed using VAS scores. Any side effects, particularly due to ketamine, like confusion, increased blood pressure or heart rate, mental or mood changes, nausea, delirium, etc., were observed. Follow-up was conducted every 2 weeks for 3 months with VAS scores, ODI score, and depression score. Patients having $\leq 50 \%$ improvement from baseline VAS with numeric analog scale (NAS) 1 or 2 after a month were given repeat block with the same drug solution. Patients having no relief were evaluated for confounding factors. The number of patients undergoing repeat blocks and the number of repeat blocks were compared and data analyzed statistically.

\section{OBSERVATIONS}

The sample size was determined to be adequate using desired power of 0.82 and alpha error of 0.05 . The primary analysis of power was done with number of repeat blocks in the two groups. Statistical analysis was done with chi-square test for nonparametric data. For parametric data, intragroup comparison was done with paired $\mathrm{t}$ test and intergroup comparison with Student's $\mathrm{t}$ test. The pain-free time till 2nd repeat block and 3rd repeat block in the two groups was compared by Kaplan-Meier survival analysis where $p$-value of $<0.05$ was considered significant.

Both the groups were comparable in terms of mean age, sex, duration of symptom, MRI findings, and preprocedure (PP) scores (Table 1 - Demographics).

Moreover, the periprocedural epidurographic findings in both the groups were comparable with respect to ventral, dorsal, and nerve root findings (Graph 1).

On each follow-up when mean VAS and ODI scores were compared with the PP values in each group (Table 2 VAS and quality of life scores), a highly significant reduction noted in both the groups with insignificant
Table 1: Demographics

\begin{tabular}{|c|c|c|c|}
\hline Group I & Group II & \multicolumn{2}{|c|}{ Statistical analysis } \\
\hline \multicolumn{4}{|c|}{ Age of the patients in years } \\
\hline \multirow[t]{2}{*}{$47.73 \pm 13.869$} & $47.43 \pm 14.115$ & NS & \\
\hline & Group I & Group II & Total \\
\hline \multicolumn{4}{|c|}{ Sex distribution of the patients } \\
\hline Male & 18 & 14 & 32 \\
\hline Female & 12 & 16 & 28 \\
\hline Total & 30 & 30 & 60 \\
\hline
\end{tabular}

$\chi$-square test; Data in no. of patients;NS-Non significant $(p>0.05)$

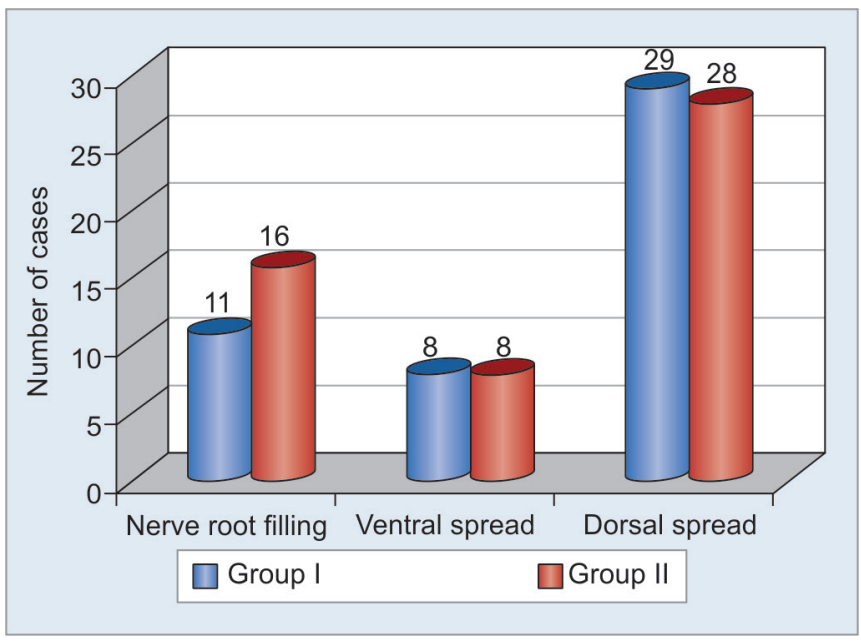

Graph 1: Periprocedural epidurographical findings

difference on intergroup comparison. On intragroup comparison, the decrease in depression score at 2 weekly follow-up from PP scores in group I was insignificant till the 1st month and then turned significant, while in group II it was highly significant at all follow-ups. This may be reflected by the fact that initial depression scores were clinically higher in group II than in group I, leading to significant reduction post block. The intergroup comparison was insignificant.

The patients undergoing repeat blocks were statistically comparable in both the groups (Table 3). However, patients of the study group required only one repeat block, whereas those of the control group required variable number of repeat blocks, with even up to three in few patients, thus indicating statistically significant reduction in requirement of repeat block with the ketamine group.

On applying Kaplan-Meier survival analysis on patients undergoing 2nd and 3rd repeat blocks, the product-time graph shows better survival without multiple repeat blocks in group I (ketamine) as compared to group II (placebo), although statistically nonsignificant $(\mathrm{p}=0.07)($ Graph 2).

No major complication was seen in both the groups except for minor complaints of heaviness in low back in 2 patients, vasovagal in 1, high random blood sugar levels in 1, 
Table 2: Vas score and quality of life score

\begin{tabular}{|c|c|c|c|c|c|}
\hline \multicolumn{6}{|c|}{ Vas Score } \\
\hline & $\begin{array}{l}\text { Group I } \\
\text { (ketamine) }\end{array}$ & & $\begin{array}{l}\text { Group II } \\
\text { (normal saline) }\end{array}$ & & Statistical Analysis \\
\hline & & w.r.t.PP & & w.r.t.PP & Intergroup \\
\hline Pre $\operatorname{pr}(\mathrm{PP})$ & $80 \pm 12.594$ & & $79.83 \pm 16.108$ & & NS \\
\hline Post pr & $34 \pm 20.611$ & HS & $35.67 \pm 21.725$ & HS & NS \\
\hline At 2 weeks & $32.33 \pm 19.772$ & HS & $29.43 \pm 17.714$ & HS & NS \\
\hline At 4 weeks & $28.5 \pm 20.475$ & HS & $26.43 \pm 18.962$ & HS & NS \\
\hline At 6 weeks & $26.33 \pm 22.702$ & HS & $28.73 \pm 20.625$ & HS & NS \\
\hline At 8 weeks & $27.67 \pm 22.657$ & HS & $29.40 \pm 22.340$ & HS & NS \\
\hline At 10 weeks & $27.67 \pm 22.922$ & HS & $30.73 \pm 24.295$ & HS & NS \\
\hline At 12 weeks & $28.00 \pm 22.152$ & HS & $32.90 \pm 26.101$ & HS & NS \\
\hline \multicolumn{6}{|c|}{ Oswestry score } \\
\hline Pre pr (PP) & $55.47 \pm 14.649$ & & $56.27 \pm 6.314$ & & NS \\
\hline At 2 weeks & $37.93 \pm 14.186$ & HS & $39.60 \pm 17.620$ & HS & NS \\
\hline At 4 weeks & $33.40 \pm 12.673$ & HS & $32.00 \pm 15.031$ & $\mathrm{HS}$ & NS \\
\hline At 6 weeks & $30.8 \pm 12.968$ & HS & $29.73 \pm 13.663$ & HS & NS \\
\hline At 8 weeks & $30.87 \pm 12.514$ & HS & $30.67 \pm 14.549$ & HS & NS \\
\hline At 10 weeks & $30.33 \pm 12.737$ & HS & $32.93 \pm 15.472$ & HS & NS \\
\hline At 12 weeks & $30.23 \pm 12.795$ & HS & $34.33 \pm 16.791$ & $\mathrm{HS}$ & NS \\
\hline \multicolumn{6}{|c|}{ Depression score } \\
\hline Pre pr (PP) & $5.73 \pm 3.667$ & & $6.27 \pm 3.012$ & & NS \\
\hline At 2 weeks & $4.13 \pm 2.874$ & NS & $4.87 \pm 2.141$ & $\mathrm{HS}$ & NS \\
\hline At 4 weeks & $4.00 \pm 3.206$ & NS & $3.87 \pm 2.175$ & HS & NS \\
\hline At 6 weeks & $3.73 \pm 3.258$ & $S$ & $3.63 \pm 2.096$ & $\mathrm{HS}$ & NS \\
\hline At 8 weeks & $3.37 \pm 2.697$ & HS & $3.70 \pm 2.389$ & HS & NS \\
\hline At 10 weeks & $3.33 \pm 2.617$ & HS & $3.90 \pm 2.797$ & HS & NS \\
\hline At 12 weeks & $3.37 \pm 2.748$ & $\mathrm{HS}$ & $3.97 \pm 2.869$ & $\mathrm{HS}$ & NS \\
\hline
\end{tabular}

Intragroup comparison- paired T test, Intergroup comparison-Student T-test. Data are Mean \pm SD; HS: Highly Significant ( $p$ value $<0.001$ ); NS: Insignificant ( $>0.05$ ); PP: Pre-procedure

Table 3: Number of repeat blocks

\begin{tabular}{lll}
\hline & $\begin{array}{l}\text { Group I } \\
(n=30)\end{array}$ & $\begin{array}{l}\text { Group II } \\
(n=30)\end{array}$ \\
\hline $\begin{array}{l}\text { Total no. of patients requiring } \\
\text { repeat blocks }\end{array}$ & 10 & $8 \mathrm{NS}$ \\
Total no. of repeat blocks & 10 & $20 \mathrm{~S}$ \\
\hline
\end{tabular}

$\chi$ - square test. Data in-no of patients; NS ( $p>0.05)$, S $(p<0.05)$. and nausea/vomiting in 1 patient with intergroup comparison being statistically insignificant. 20 out of 30 patients in group I experienced shortlasting delusions $45 \pm 10$ minutes post the block, which may be due to the systemic absorption of ketamine through the epidural space and intergroup comparison being statistically highly significant.

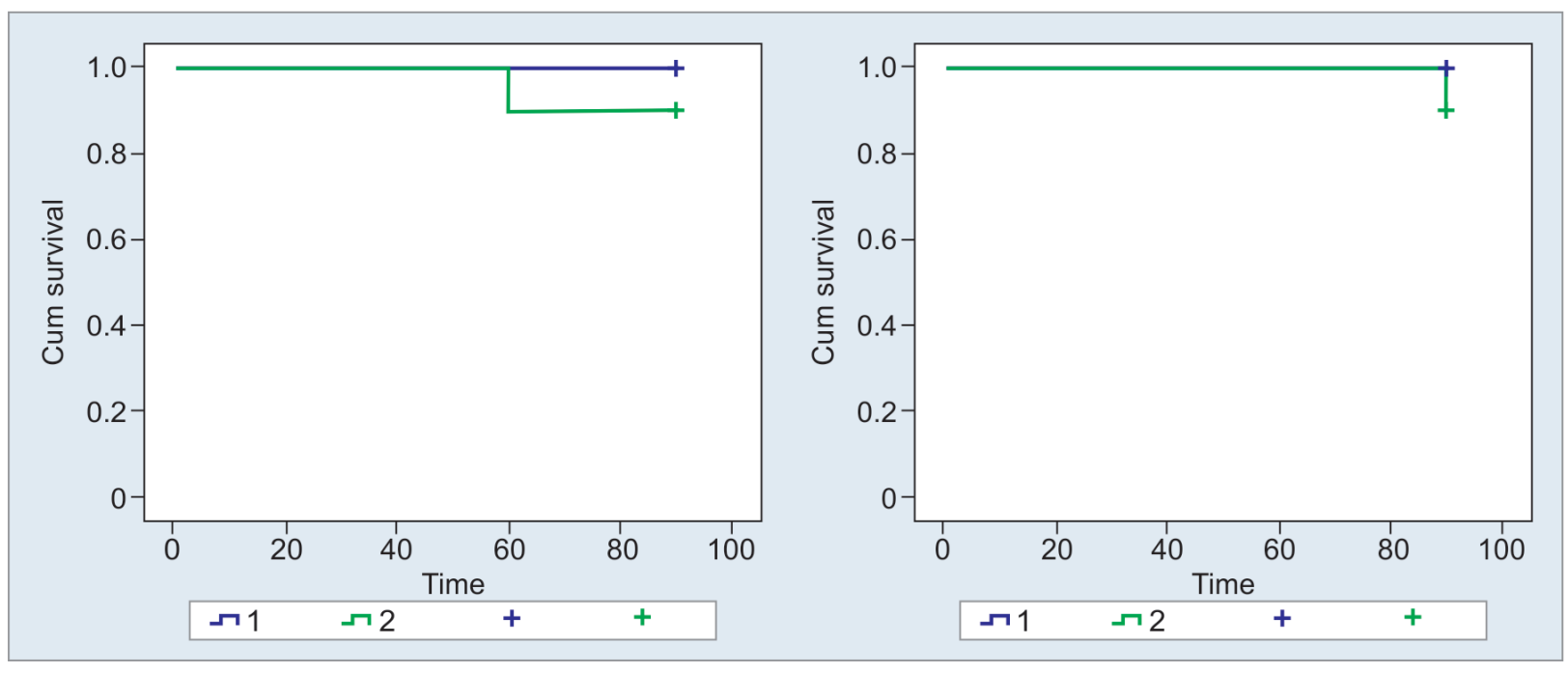

Graph 2: Kaplan-Meier survival curve for pain-free time after 1st repeat block 


\section{DISCUSSION}

Lumbar epidural steroid injections are the interventions that offer remission from mechanical, inflammatory, degenerative, and neuropathic LBA. This can be mainly attributed to the antiinflammatory effects of corticosteroids via blockage of nociceptive C-fiber conduction, inhibition of prostaglandin synthesis, improved microcirculation, and reduced ischemia. ${ }^{6}$ Addition of local anesthetic in epidural injection also inhibits the afferent nociceptive $C$-fibers and dilutes inflammatory mediators. Many approaches, such as midline, parasagittal, transforaminal, and caudal have been used for epidural steroid injections and all proved advantageous in relieving pain of chronic LBA.,

However, in patients with "red flag" signs or those depicting severe mechanical origin of LBA, often multiple steroid injections are required which associated with longlasting side effects. Thus, a research on adjuvants has been started that could enhance the efficacy of epidural steroids and reduce the number of repeat blocks in these patients.

Ketamine has been widely studied as an adjuvant in various persistent chronic pains. It may complement the pain relief attained by epidural steroids due to its action on NMDA receptors, suppressing the element of dorsal horn "wind up" and its effects through opioid receptors. Moreover, its local anesthetic properties in higher doses may probably be an another reason.

In this study, ketamine as preservative-free product has been used epidurally. It has also been used intrathecally for perioperative pain management. ${ }^{9-13}$ It is commercially available in ampoule form. ${ }^{14}$

The rationale for using $30 \mathrm{mg}$ ketamine in our study was based on previous studies where comparative doses of 0.3 to $0.5 \mathrm{mg} / \mathrm{kg}$ epidurally with or without opioids for perioperative as well as chronic pain, but a single bolus dose of $30 \mathrm{mg}$ gave adequate longlasting analgesia with minimal side effects. ${ }^{15-19}$ Researches on low (2-3 mL) vs high volume $(6-10 \mathrm{~mL})$ of injectate with same weight of drugs have yielded superior results with higher volumes. So, the dilution of drug mixture to $6 \mathrm{~mL}$ with $0.25 \%$ bupivacaine was used for this study. ${ }^{20}$

The VAS scores did not improve significantly by addition of ketamine to epidural steroids, which can be explained by the slow binding of ketamine to NMDA receptors. ${ }^{21}$ Hence, a single bolus injection, as performed in the present protocol, most likely did not achieve complete receptor saturation to provide additional analgesia over and above the antiinflammatory action of steroid.

Although little is known about the pharmacokinetics of epidural ketamine in humans, Pedraz et al, ${ }^{22}$ in a study on dogs, showed that racemic ketamine was rapidly absorbed from the epidural space into the cerebrospinal fluid and plasma with a longer half-life than if applied intravenously. Thus, epidural ketamine gets distributed rapidly into the systemic circulation after administration, which may have diluted its effect on the NMDA and opioid receptors causing inadequate response of single-dose ketamine in chronic LBA. Our patients also responded well after 1st repeat block, may be due to cumulative effect of two doses, as one dose was insufficient.

Also, the amount of ketamine used in the present study may not have been sufficient to provide longlasting pain control. This is contrary to the studies conducted by Amr, ${ }^{23,24}$ where addition of $30 \mathrm{mg}$ ketamine in a bolus dose to $80 \mathrm{mg}$ triamcinolone produced highly significant reduction in VAS, may be due to different study design.

A comparable results were found in ketamine group ws control group where 10 and 8 patients were given repeat block respectively. However, single repeat block provided a pain relief for 2 months in all patients who underwent repeat procedure with ketamine (group I), while in group II (placebo-control) two to three repeat blocks were required in some patients, thus the total number of repeat blocks being significantly lower in group I (ketamine). This finding reflects that with repeated use, the action of ketamine as an adjuvant to epidural steroids might have been able to achieve NMDA receptor saturation. Also, on Kaplan-Meier survival analysis, though p-value $>0.05$ (0.078), but the graph showed longer pain-free time till repeat block with addition of ketamine than with saline used as placebo.

Another study by Rahimzadeh et al compared painfree time by addition of hyaluronidase to epidural steroid in postspine surgery patients and found greater pain reduction with the former. Also, the analysis showed better survival on Kaplan-Meier analysis in patients with disk herniation than stenosis though statistically insignificant $(p>0.05){ }^{25}$

Lauretti et al in a study carried out by inserting an epidural catheter in patients with low back pain, gave ketamine $0.1 \mathrm{mg} / \mathrm{kg}$ with lidocaine $1 \%$ three times a day for 3 weeks in one set of patients, as opposed to another set where clonidine $30 \mathrm{mg}$ was used with lidocaine $1 \%$ thrice daily. He reported that epidural ketamine when used as an adjuvant to lidocaine was as efficacious as clonidine for control of refractory chronic low back pain. Visual analog scale was maintained at 0 to 3 during the epidural ketamine administration and continued for 2 to 5 weeks later. ${ }^{26}$

The quality of life scores are very important to investigate whether pain improvement by LESI helped the patient in coping up with their usual professional and social lives as seen by drastic reduction in ODI and depression scores in both the groups in our study, with no statistical intergroup difference. 
Twenty out of thirty patients in ketamine group experienced shortlasting delusions $45 \pm 10$ minutes in duration, which were not bothersome as they subsided by itself without any medication. In humans, a single epidural injection of $5 \mathrm{mg}$ of ketamine entered the systemic circulation with $80 \%$ bioavailability. ${ }^{27}$ This rapid plasma distribution might have been responsible for the psychodysleptic effects produced after administration of epidural ketamine.

Eight patients in group I and 11 patients in group II required analgesics for pain management, which was statistically insignificant on intergroup comparison. However, physiotherapy was advised to all patients, which improved the physical and mental status of the patient. ${ }^{28}$

\section{Strengths}

The conception of this research was based on the knowledge of ketamine as a potent analgesic inhibiting chronic pain pathways, as well as its newly described role in inflammatory cascade modulation. Low backache arising out of different neurobiological derangements in tissues forming spine was known to respond to epidural steroids but with repeated blocks lead to systemic side effects. We hypothesized that addition of ketamine to steroids could lead to additional analgesia and reduced repeat blocks.

\section{Limitations}

Majority of patients suffered shortlasting "delusions" in the ketamine group, thus, for the postprocedural assessors, blinding was not achieved. Also due to limited timeframe available, the longterm efficacy of ketamine in chronic LBA could not be evaluated.

\section{IMPLICATIONS}

Thus to conclude, ketamine's analgesic properties, keeping in account its pharmacokinetics and dynamics in the epidural space, can be exploited in future era to reduce the frequency of epidural steroid injections in LBA patients who suffer the plight of central neuropathic or mixed pain syndrome by prolonging their pain-free interval. As ketamine is available for use through different routes, these can be compared as a matter of further research.

\section{REFERENCES}

1. Wani A, Habib M, Tantray MD, Kuchey GA, Singh D. Our experience with epidural steroid injections in the management of low back pain and sciatica. Intern J Orthop Surg 2012;19(2):1-6. [cited 2014 Nov 14]. Available from: http:// ispub.com/IJOS/19/2/13781

2. Braddom RL. Chronic pain. In: DeLisa JA, Gans BM, Walsh NE, editors. Physical medicine and rehabilitation: principles and practice. 4th ed. Philadelphia, PA: Lippincott Williams and Wilkins; 2005. p. 518.

3. Leary J, Swislocki A. Hypothalamic-pituitary-adrenal suppression and iatrogenic Cushing's syndrome as a complication of epidural steroid injections. Case Rep Endocrinol 2013;Article ID 617042:4. Available from: http://dx.doi. org/10.1155/2013/617042.

4. Pocket S. Spinal cord synaptic plasticity and chronic pain. Anesth Analg 1995 Jan;80(1):173-179.

5. Sandkuhler J. Learning and memory in pain pathways. Pain 2000 Nov;88(2):113-118.

6. Rydevik BL, Cohen DB, Kostuik JP. Spine epidural steroids for patients with lumbar spinal stenosis. Spine 1997 Oct;22(19):2313-2317.

7. Sandhu N, Gupta R, Singh S, Aujla KS, Kaur M, Bindra T. Clinical outcome and fluoroscopic comparison of two different approaches of epidural steroid in low backache patients. J Evol Med Dent Sci 2014 May;3(19):5161-5171.

8. Gupta R, Singh S, Kaur S, Singh K, Aujla K. Correlation between epidurographic contrast flow patterns and clinical effectiveness in chronic lumbar discogenic radicular pain treated with epidural steroid injections via different approaches. Korean J Pain 2014 Oct;27(4):353-359.

9. Subramaniam K, Subramaniam B, Pawar DK, Kumar L. Evaluation of the safety and efficacy of epidural ketamine combined with morphine for postoperative analgesia after major upper abdominal surgery. J Clin Anesth 2001 Aug;13(5):339-344.

10. Koinig H, Marhofer P, Krenn CG, Klimsca W, Wildling E, Erlacher W, Nikolic A, Turnheim K, Semsroth M. Analgesic effects of caudal and intramuscular S(+)-ketamine in children. Anesthesiology 2000 Oct;93(4):976-980.

11. Pattar A, Silomon M, Werth M, Ziegeler S. Epidural vs subcutaneous application of s-ketamine for postoperative pain management after total knee replacement. Eur J Anaesthesiol 2010 Jun;27(47):205.

12. Ozyalcin NS, Yucel A, Camlica H, Dereli N, Andersen OK, Nielsen LA. Effect of pre-emptive ketamine on sensory changes and postoperative pain after thoracotomy: comparison of epidural and intramuscular routes. Br J Anaesth 2004 Sep;93(3):356-361.

13. Marhofer P, Krenn CG, Plöchl W, Wallner T, Glaser C, Koinig H, Fleischmann E, Höchtl A, Semsroth M. S(+)-ketamine for caudal block in paediatric anaesthesia. Br J Anaesth 2000 Mar;84(3):341-345.

14. Adams HA, Werner C. From the racemate to the eutomer: (S)-ketamine. Renaissance of a substance? Anaesthesist 1997 Dec;46(12):1026-1042.

15. Choe H, Choi YS, Kim YH, Ko SH, Choi HG, Han YJ, Song HS. Epidural morphine plus ketamine for upper abdominal surgery: improved analgesia from preincisional versus postincisional administration. Anesth Analg 1997 Mar;84(3):560-563.

16. Wong CS, Lu CC, Cherng CH, Ho ST. Pre-emptive analgesia with ketamine, morphine and epidural lidocaine prior to total knee replacement. Can J Anaesth 1997 Jan;44(1):31-37.

17. Yang CY, Wong CS, Chang JY, Ho ST. Intrathecal ketamine reduces morphine requirements in patients with terminal cancer pain. Can J Anaesth 1996 Apr;43(4):379-383.

18. Naguib M, Adu-Gyamfi Y, Absood GH, Farag H, Gyasi HK. Epidural ketamine for post operative analgesia. Can Anaesth Soc J 1986 Jan;33(1):16-21.

19. Wong CS, Shen TT, Liaw WJ, Cherng CH, Ho ST. Epidural coadministration of ketamine, morphine and bupivacaine 
attenuates post-herpetic neuralgia - A case report. Acta Anaesthesiol Sin 1996 Sep;34(3):151-155.

20. Chun EH, Park HS. Effect of high-volume injectate in lumbar transforaminal epidural steroid injections: a randomized, active control trial. Pain Physician 2015 Nov;18(6):519-525.

21. Bonhaus DW, McNamara JO. N-methyl-D-aspartate receptor regulation of uncompetitive antagonist binding in rat brain membranes: kinetic analysis. Mol Pharmacol 1988 Sep;34(3):250-255.

22. Pedraz JL, Calvo MB, Gascon AR, Hernandez R, Muriel C, Torres LM, Dominguez-Gil A. Pharmacokinetics and distribution of ketamine after extradural administration to dogs. Br J Anaesth 1991 Sep;67(3):310-316.

23. Amr YM. Effect of addition of epidural ketamine to steroid in lumbar radiculitis: one-year follow up. Pain Physician 2011 Sep-Oct;14(5):475-481.

24. Amr YM. Epidural ketamine in post spinal cord injury-related chronic pain. Anesth Essays Res 2011 Jan-Jun;5(1):83-86.
25. Rahimzadeh P, Sharma V, Imani F, Fair HR, Ghodrati MR, Nikzad-Jamnani AR, Nader ND. Adjuvant hyaluronidase to epidural steroid improves the quality of analgesia in failed back surgery syndrome: a prospective randomized clinical trial. Pain Physician 2014 Jan-Feb;17(1):75-82.

26. Lauretti GR, Rodrigues AM, Gomes JMA, Reis MP. Epidural ketamine versus epidural clonidine as therapeutic for refractory neuropathic chronic pain. Rev Bras Anestesiol Campinas 2002 Jan-Feb;52(1):34-40.

27. PedrazJL,LanaoJM,Calvo MB, MurielC,Hernandez-Arbeiza J, Dominguez-Gil A. Pharmacokinetic and clinical evaluation of ketamine administered by i.v. and epidural routes. Int J Clin Pharmacol Ther Toxicol 1987 Feb;25(2):77-80.

28. Henchoz Y, Goumoens P de, Norberg M, Paillex R, So AKL. Role of physical exercise in low back pain rehabilitation - a randomized controlled trial of a three month exercise program in patients who have completed multidisciplinary rehabilitation. Spine 2010 May;35(12):1192-1199. 